\title{
The influence of electric power system reform on State Grid Ningxia Electric Power Company
}

\author{
Hui Li ${ }^{1, a}$, Shulin $\mathrm{Li}^{2, b}$ \\ ${ }^{1}$ State Power Economic Research Institute China State Grid Corp, Beijing, China \\ ${ }^{2}$ Department of Economic Management \\ North China Electric Power University, Baoding, China \\ aemail: email: bjgw_Ih@163.com, ${ }^{b}$ email: Islzg@foxmail.com
}

\begin{abstract}
Keywords: New electricity reform; Electric power company; Influence
Abstract. With the deepening of the new round of electric power system reform process, the provincial Power Grid Corp will be under the new electricity reform policy proposed the corresponding reform program. This paper first analyzes the background of a new round of electricity reform and the current situation of Ningxia Prov-ince, and made clear the core idea of Ningxia electric power system reform program, and then studied the op-eration mode of Ningxia province; On this basis, combined with the new electricity reform ideas, from the two aspects of the interests of the company focused on the analysis of the impact of the company in Ningxia Province, the new electricity reform will have a great impact on the power grid operation mode, business scope, profit and so on.. Therefore, this paper can provide some reference for decision makers.
\end{abstract}

\section{Background and current situation of electric power system reform}

After a lapse of 12 years, the power system reform in the context of China's comprehensive deepening of institutional reform, once again to open the curtain. The driving force of this round of reform, in fact, is a combination of old contradictions and new problems[1]. After more than 10 years of development, China's power industry has basically solved the problem of power shortage within the country, the business capacity has been significantly improved, the whole system is more healthy operation. But the power industry is still facing some problems, specifically can be summarized into two aspects: first, the remaining problems become serious, the second is the emergence of new challenges[2,3].

These two points constitute the core motivation to promote a new round of electricity reform. With the slowdown in China's economic growth, the overall demand for electricity energy growth will be in a relatively flat period, the appropriate and moderate reform of the industry environment basically have [4,5]; at the same time, the voice of the reform of China's monopoly industry is getting higher and higher, the reform of the environment has been formed, the new electricity reform is imperative [6].

For Ningxia Province, Ningxia is the provincial-level area approved by the State Development and Reform Commission for the second program of transmission and distribution price reform. Development and Reform Commission approved the "Ningxia power grid transmission and distribution price reform pilot program", and asked the Ningxia as soon as possible to develop 2016 2018 regulatory period in Ningxia power grid transmission and distribution of income and price levels of the calculation program.

Ningxia pilot program provides that the transmission and distribution price of the approved range for the national network of Ningxia Electric Power Company all share the price of network transmission and distribution services. The basis of the approved price for the State Grid Ningxia Power Company's transmission and distribution assets and business. The transmission and distribution price reform plan of Ningxia is similar to the previous Mengxi's plan. Overall, the content of the Shenzhen pilot program was continued. In accordance with the principle of "allowable cost plus reasonable income", the power grid enterprises were subject to the supervision of the total revenue, and the power transmission and distribution tariffs were separately accounted for[7]. 


\section{Company operation mode}

State Grid Ningxia Electric Power Company is a wholly-owned company of State Grid Corporation of China, with the core mission of building and operating power grids. It undertakes the basic mission of ensuring a safer, more economical, cleaner and more sustainable power supply. State Grid Ningxia Electric Power Company will comprehensively and thoroughly implement the State Grid Corporation to build two first-class development goals, and actively promote intensive, flat, professional management, to achieve the company's development mode of change; Speed up the construction of UHV power grids and smart grids to achieve power grid development mode change. The capacity of the company's security, resource allocation, capital operation, assets profitability, scientific and technological innovation and risk prevention were significantly improved, the management modernization level, quality service level, staff quality and brand image improved significantly, In the promotion of sustained and healthy economic development and rapid development in the modernization process it has played a significant role. The company basically built a strong network of strong, excellent quality, service quality, excellent performance, the leading domestic and international first-class modern enterprise.

The current mode of operation of the company is responsible for the province of transmission, substation, distribution and other full-chain business operations. From the company's power grid planning, construction of power grids, dispatch control power grid, operation and maintenance of power grids, electricity sales and power supply services, the company's business has penetrated every aspect (such as transmission and distribution of all physical transmission links, capital flows, business operations). The company is responsible for the purchase of electricity from hydropower, thermal power, nuclear power, wind power and other power sources, and through power control and marketing of electrical energy products to agriculture, industry, commerce and other industries, and power supply for the residents.

In addition, the performance of the company's operations have a greater dependence on the government policy support. The difference between the current purchase price and the selling price of the company is 200 yuan / $\mathrm{KWH}$, and the gross profit of the company is RMB 60 billion yuan, based on the annual sales volume of 300 billion kwh. High gross profit margin has become the main source of power to promote the company's large-scale investment in fixed assets, high consumption of power grid operation and maintenance, the company's management and control costs. After the new electricity reform, the purchase price of the spread will be gradually replaced by the cost of pricing, 300 billions kwh electricity market will be part by competitors share. Company operating performance will be seriously affected.

\section{The influence of the new electric power system reform on the State Grid Corporation of Ningxia Province}

\section{Brief introduction of new electric power system reform plan}

The new electricity reform program has not yet given the details, but the basic content has been more clear. Compared to the previous public expectations, although the new scheme may not involve splitting the grid, scheduling independent, but the grid profit model changes will also lead to a profound change in the electricity market structure.

Separation of transmission and sale

The new electricity reform plan based on the power grid and the sale of electricity separately, and clear power grid enterprise public service attributes, focusing on "four open, an independent, a strengthening", that is open price outside the transmission and distribution of operating electricity, open up the incremental distribution business, open the public welfare and regulation outside the power supply plan, the trading platform independent and strengthen the planning[8,9].

\section{Scheduling, transmission and distribution integration}

Transmission, distribution and scheduling separation are not within the scope of this power system. Power dispatching is an integrated management means, which is the basic function of power grid regulation and Can guarantee the safe operation of power grid, reliable power supply, production and orderly. As to the necessity of transmission and distribution separation, it has been questioned by some people, mainly because there is no absolute and stable division basis for transmission and distribution, and also are not suitable for future intelligent network development. Therefore, their temporary 
integration is reasonable, not only to protect the safety of the power grid, but also does not affect the market competition (CPC Central Committee and State Council on deepening the reform of state owned enterprises in the guidance of the non-ferrous metallurgical energy saving2015).

\section{The influence of the new electric power system reform}

Overall, the new round of electricity reform continue to maintain a complete transmission grid and operation, which allows the company owned by the large power grid to maintain a good sustainable development, but the release of the sale of electricity business and other reform measures will give the company Business development, power grid security brings a more profound impact, and will also impact the current business model[10,12]. The following describes the impact of the new electricity to the company from the two aspects of interest.

\section{Advantageous aspect}

a) Keep control of inter-district grid across the province

At present, the company has entered a period of special high-voltage comprehensive promotion, extra large AC and DC hybrid power grid has been gradually formed, the contradiction of power grid operation security is outstanding, and the operation characteristic is complex, a variety of stability constraints exist. So that Ningxia company's operation and control of large power grids become difficult, the power grid is facing the "tonic weak cross" features obvious, the grid out of the channel flow control difficult, stable damage and large-scale power failure risk always exists. Power system reform maintain the unity of the large power grid, which is conducive to promoting the control of large power grids, continue to maintain a good margin of stability and prevent large-scale blackout events.

b) Accelerate the construction of a unified power market at the provincial level or above

The marketization of electricity is the process of changing the allocation of power resources from the government to the market. The reform put forward "the orderly liberalization of public welfare and regulatory outside power plan", "open transmission and distribution outside the competition part of the price", "to promote the sale of electricity side reforms Which is conducive to the construction and increase the market for the main body, to produce the province's power market structure which have "multiple buyer - seller", to protect the Ningxia power grid fair and non-discriminatory open. This will provide a clear and transparent price signal for power generation enterprises and power users, guide the optimal allocation of power resources through the market mechanism, restore the unified electricity market in the province and promote market development and growth.

c) Is conducive to the company to obtain a stable income, reduce the use of electrical characteristics, such as the impact of the upstream and elastic fluctuations of downstream industries

In the transmission and distribution price reform, the government calculate the transmission and distribution permit costs and benefits, which will be from the price mechanism to ensure that electricity prices are not significantly affected by electricity market characteristics, market competition, free from fluctuations in coal prices, the wet period and dry season, it can obtain the relatively stable transmission and distribution income and protect the power grid investment demand.

d) The release of the company's reform pressure

The implementation of reform measures such as the distribution of electricity distribution business, the independent operation of trading institutions within the company and the transmission and distribution of electricity price will, to a certain extent, resolve the external challenge and alleviate the pressure of reform to create a favorable environment for the development of the company.

e) Enhance public relations with the government

Meet the national reform of public services business blueprint design requirements, and ensure the safe operation of large power grid, to ensure the safety of power supply area, full, friendly to participate in the work of energy-saving emission reduction, the practice of corporate social responsibility. The reform can also continue to optimize the relationship between the company and the Ningxia provincial government, better for the government and the people of the province.

f) Dredge the contradiction between the power plant and the power grid

Ningxia Province, the proportion of coal-fired units accounted for a large proportion of the total installed capacity. In the case of power supply exceeding demand in the province, the multi time period of coal-fired units in low power operation, and even the mediation. In this regard, the system of various power plants through various channels to exert pressure on the provincial power companies, power plants and power grid gradually increase the contradiction. After the electricity reform, the public welfare and regulatory outside of the electricity supply plans to open, the power plant participate in the 
bidding, the Internet side will rebuild the free market and will greatly ease the contradiction between the plant network.

g) Ease the pressure on electricity regulation

In the past few years, the electricity regulatory agencies are mainly engaged in network access permits, engineering installation qualification approval work, and gradually broadened to monitoring companies, including project bidding, scheduling production, power supply services and other multi-faceted. Power companies have been the focus of the relevant regulatory agencies inspectors. Through the electricity reform, will greatly promote the company to participate in public and transparent market behavior, but also makes the focus of electricity regulatory decentralization, ease the company's electricity regulatory pressure.

\section{Adverse aspect}

a) Liberalization of the sale of electricity business, incremental power distribution business, the company will give the company's market coverage and possession of a huge challenge

The release of the sale of electricity business and incremental distribution business will bring enormous pressure on the company's operations, the company's market share, operating income is facing the risk of decline. With the advance of the placement of the electricity business, the company is facing the loss of customers, market share, reduce the risk of selling electricity profits. In particular, the power generation enterprises engaged in the placing of electricity business, will occupy a larger market share, the company's electricity market has a greater impact on the market. At the same time, let go of the distribution business, may promote the formation of a number of independent placement of electrical integration of enterprises, but also will bring competitive pressure on the company's business.

b) The profit structure of the company will be greatly changed

At present, the main source of profit is the purchase price and sale price difference. The situation can also be seen from the sale of electricity components (Ningxia Province), the general industrial, commercial and large industrial use of electricity accounted for a higher proportion, but also makes the average price of the sale in a higher position. In the sales price, after deducting price, government funds and additional loss, Ningxia's average transmission and distribution price is relatively high.

After the reform, the average transmission and distribution price will be approved by the government, the introduction of market competition, industrial and commercial, large industrial electricity and other electricity markets will face fierce competition, the company will greatly reduce the transmission and distribution price, the company's profit structure and the total will be substantial Reduce the company's profitability is not optimistic.

c) Increase the risk of electricity recovery, the company accounts receivable will be a substantial increase in bad debt losses are also synchronized to expand

After the new electricity reform, power seller market situation will be reversed, in order to ensure the company's customer resources are not lost, the company must face the problem of increasing the risk of electricity recovery, the company needs to account for the market share of customers and whether the tariff can be recycled in two respects to weigh the trade-offs, bad debts may increase.

In addition, the company's high voltage users to reduce the risk of recovery of electricity charges will be reduced. Risk control electricity mainly include: divided into settlement paid, staging allocation carried forward, common advance carryover, meter card, prepaid card transfer, electricity bill back less fill, guarantee agreement etc. By the company's competitive factors in the market, the proportion of electricity tariff settlement and allocation will fall, the effective agreement guarantees will be reduced.

d) The long-term investment income of the government and the legal person has declined, and the control of the Power Grid Corp to the state-owned assets has declined further

After the power system reform, the company's operating income, operating profit will decline, the price level dropped, the company's new distribution network by the larger competition in assets, while the company faced difficulties in the cost of pressure drop, resulting in lower profits. Accordingly, the owner's equity (capital reserve, surplus reserve, undistributed profit, etc.) of the company will decrease, while the power grid company is the state-owned enterprise, the government state and the legal person enterprise is the investment subject of the company, the ownership interest of the company drops, In the debt to maintain a considerable level of conditions, will also lead to state-owned assets in various forms of transfer, the power company's control of state-owned assets and scale will be reduced.

e) Cost management and control of binding changes

Open transmission and distribution outside the operating price, the company all kinds of business costs and investment will be a strong regulation. In the case of company cost constraints, can only 
establish a variety of standard cost system, and the controllable costs of pressure drop, reduce grid operating costs, cost control constraints to strengthen. At the same time, in recent years, the cost of research and development of special high-voltage power technology will be substantially reduced, resulting in the company's core competitiveness.

f) The situation of brain drain has become more and more serious

With the deepening of reform, the market for the power of the people's desire will lead to the accumulation of talent prices rise, high-end distribution network production and marketing personnel will gradually be recognized and sought after by the human resources market. Finance, transport inspection, marketing professionals will lose the peak, especially the marketing professional from the cause of expansion, electricity inspection, power supply service and other aspects of the talent will be the loss of focus, and the prediction to the Employee terminates the labor contract will gradually become the highest proportion of the loss of the way.

g) With the increase of the market main body, the uncertainty of the operation mode and the flow direction of the power grid is increasing, which brings some challenges to the safe operation of the company's power grid

After the power generation plan and the sale side market are released, the market transaction and operation mechanism is still in exploration. With the development of short-term transactions such as monthly, pre date, the uncertainty of power grid operation mode and flow direction increases, which makes it more difficult to ensure the safe and stable operation of power grid. At the same time, distributed energy becomes the main power of the sale, and the distribution network must be connected, which will have a certain impact on the safe operation of the power grid.

h) While the current trading institutions remain relatively independent of the company's internal operations, but the next step is entirely independent of whether the transaction depends on the extent of the company's fair transparency in the trading organization

If the company can not effectively protect the power of open and transparent transactions, and now the relative independence of the establishment of the transaction may become the future of the transaction which will be completely independent of the grid companies transition model, and changes in the settlement by the way the company's earnings. Once the trading organization is independent, the company will lose control of the transaction organization, if the transaction is also completed by the independent transaction, will affect the company's cash flow, the company has a significant impact.

i) On the power grid to strengthen the fair and open, the company is facing cost transparency, information disclosure, power supply and other aspects of the regulatory pressure to increase

With the increase in market players, the main body will further strengthen the company's transmission and distribution cost supervision. At the same time, regulators may also speed up the scheduling transactions, power and quality of service information disclosure, and further require companies to disclose relevant information.

\section{Conclusions}

With the new round of power system reform, the provincial company will gradually push forward the reform process, the new electricity reform policies and ideas will have a significant impact on the provincial company, will completely break the grid company chain business model. The province's transmission, substation, power distribution and other full-chain business operations will be cut off, which will also change the company's mode of operation and business scope. In addition, from the company's economic point of view, the new electricity reform will completely change the company's profit model (that is, cost plus a reasonable profit approach), the new electricity reform on the company's revenue have a significant impact. In short, by analyzing the core idea of the new electricity reform policy, combined with the reform proposal submitted by the company in Ningxia, summed up the impact of the new electricity reform on the Ningxia company from the two sides. Therefore, this article will provide some reference for the company in Ningxia.

\section{Acknowledgments}

In this paper, the research was sponsored by the National grid science and technology project of China State Grid Corp(Project Name: Research on the method and application of reasonable investment of 
Power Grid Considering the difference of development needs) and the Key projects of basic scientific research business of Central University(Project No.2014ZD21).

\section{References}

[1] Zhang Zixiao. The influence of electric power system reform on power grid enterprise [J]. enterprise reform and management, 2016,08:192.

[2] Wang Xiaojun. Countermeasures for the power enterprises to manage the electric power enterprises according to law under the new situation $[\mathrm{J}]$. enterprise reform and management, 2016,08:217.

[3] Chen Zhen, Ge Zhijian. On the electric power system reform in China from the perspective of Uber model[J]. energy, 2015,09:107-109.

[4] Zhang Senlin, Sun Yanming. Electric power system reform and the influence of power market on the Southern Power Grid [J]. Guangdong electric power, 2012,11:1-5.

[5] Wang Yingnan, Gao Peina. The development of smart grid effect on Reform of electric power system [J]. Heilongjiang science and technology information, 2013,12:126.

[6] Shi Dan. The goal of China electric power system reform [J]. China energy, 2014,08:69-47.

[7] Liu Bin. Discussion on the system reform of power grid enterprises impact on [J]. Chinese (Electrical Technology Edition), 2014,11:160-163.

[8] Li Zhimin. Comparative analysis of the power system reform in China and the UK [D]. Anhui University, 2013.

[9] Wang Lei, Wang Zhaopo. Research on the path of increasing enterprise economic value added in electric power enterprises [J]. Heilongjiang science, 2015,12:126-129.

[10] Comprehensive interpretation. The electricity market [J]. Yunnan electric power, 2015,11:4-6.

[11] Wang Shuai, Ning Sun, Yan Haibin. Power marketing management of power supply enterprises of [J]. science and Technology Economic Herald, 2015,15:173-174.

[12] Shen Hongyu, Chen Jin, SYC, Tan Jian, Wang Zhe, Li Yang. The influence of the new round of electric power reform on distribution network planning of power grid enterprises and Countermeasures [J]. electric power construction, 2016,03:47-51. 